\title{
The Effect of Elevated Temperature on Engineered Cementitious Composite Microstructural Behavior: An Overview
}

\author{
Mohamad Hakimin Khazani ${ }^{1}$, Oh Chai Lian ${ }^{1 *}$, Lee Siong Wee², Mohd Raizamzamani \\ Md Zain ${ }^{1}$ and Norrul Azmi Yahya ${ }^{1}$ \\ ${ }^{1}$ School of Civil Engineering, College of Engineering, Universiti Teknologi MARA, 40450 UiTM, Shah Alam, \\ Selangor Darul Ehsan, Malaysia \\ ${ }^{2}$ School of Civil Engineering, College of Engineering, Universiti Teknologi MARA Johor, Pasir Gudang Campus, \\ 81750 UiTM, Masai, Johor, Malaysia
}

\begin{abstract}
This paper discusses the quantitative bibliographic data derived from scientific publications on Engineered Cementitious Composites (ECC) subjected to elevated temperature, the influence of elevated temperature on the mechanical properties, particularly the compressive strength and microstructure behavior of Engineered Cementitious Composites (ECC) mixtures based on the review of previous pieces of literature. Systematic literature reviews were employed as the methodology in this study. The age of related publications selected to be reviewed was limited to publications for the past ten years, 2010 to December 2020. It was found from available research that exposure of the ECC specimen at the elevated temperature starting from $200^{\circ} \mathrm{C}$ significantly reduced the compressive strength when the temperature increases, melting of fiber and increase of porosity causes the dramatically increase micro-cracks.
\end{abstract}

ARTICLE INFO

Article history:

Received: 26 May 2021

Accepted: 15 September 2021

Published: 10 January 2022

DOI: https://doi.org/10.47836/pjst.30.1.24

E-mail addresses:

hakiminkhazani96@gmail.com (Mohamad Hakimin Khazani)

chailian@uitm.edu.my (Oh Chai Lian)

leesiongwee@uitm.edu.my (Lee Siong Wee)

raizam@uitm.edu.my (Mohd Raizamzamani Md Zain)

norrulazmi@uitm.edu.my (Norrul Azmi Yahya)

* Corresponding author
Keywords: Cracks, Engineered Cementitious Composites (ECC), elevated temperature, fiber, microstructure, scanning electron microscope (SEM)

\section{INTRODUCTION}

Engineered Cementitious Composite (ECC) is a special type of High-Performance Fiber Reinforced Cementitious Composites, distinct for tensile strain-hardening behavior and tensile ductility compared to the quasibrittle design of conventional concrete 
and fiber-reinforced concrete (Huang \& Zhang, 2014; Khan et al., 2021). ECC has demonstrated excellent uniaxial tensile strain capacity of 3-5\% (about 300-500 times higher than conventional concrete, which is $0.01 \%$ ) and tight crack width of about $40 \mu \mathrm{m}$ (Li, 2003; Ma et al., 2015). ECC incorporates industrial waste has also been studied for more greener and sustainable construction materials (Booya et al., 2020; Chen et al., 2013; Lee et al., 2019). The use of ECC has expanded dramatically over the last decade and has been used in a number of systems, such as high-rise buildings (Yang et al., 2021), bridges (Zhang et al., 2021), tunnels (Huang et al., 2021), highways (Guan et al., 2021) and other infrastructures. ECC is suggested in strengthening beam-to-column connections that are recurrently exposed to cyclic loading, a continuous and repeated loading, such as fluctuating stresses, strains, and forces, seismic actions (Lee et al., 2018; Qudah \& Maalej, 2014). The ECC-concrete beams with ECC application at the tension region, when subjected to flexural load, displayed a substantial improvement in flexural strength and ductility, proven under both the experimental and theoretical aspects (Yuan et al., 2020; Zhang et al., 2006).

The study of rheological and mechanical properties of the ECC especially dealing with the risk of exposure to elevated temperatures has recently attracted attention. Table 1 shows the previous studies on ECCs subjected to elevated temperature, with different raw materials applications, geometry specifications, experimental testing, and heating parameters. It is found from Table 1 that common raw materials in ECCs are cement, mineral admixtures (i.e., silica fume, limestone powder, fly ash), sand (i.e., river, sand), fibers (i.e., PVA, $\mathrm{PE}$ ), and superplasticizer. Previous studies investigated strength performances of ECC specimens under room temperature and temperatures at a range of $50^{\circ} \mathrm{C}$ to $1200^{\circ} \mathrm{C}$. The ECC specimens were subjected to a heating rate of $4.4^{\circ} \mathrm{C} / \mathrm{min}$ to $23.5^{\circ} \mathrm{C}$ with heating exposure for 1-2 hours. High temperature can cause changes in the physical and chemical properties of the ECC, which further affect the mechanical properties and microstructural behavior of the material. The effect of the elevated temperature on mechanical properties, particularly compressive strength and microstructural behavior, such as deterioration of fiber and microcracking that reduce the durability of the ECC, was seen clearly (Şahmaran et al., 2011). It is, therefore, necessary to fully understand the effects of high temperature on ECC so that the applications of ECC could be more effective and sustainable.

This paper presents an overview of the effects of elevated temperature on the microstructural behaviour of ECC. The systematic and integrative reviews were used as the methodology in this study. This study focuses on the selected related research articles limited to recent ten-years publications. This paper consists of four sections. Section 2 presents the methodology of the literature review. Section 3 presents the results of the bibliometric analysis of the topic. Section 4 discusses the effects of elevated temperature on the compressive strength, deterioration of fibers, and microcracking behavior of ECC. Finally, Section 5 presents the conclusions. 
Elevated Temperature on ECC Microstructural Behavior: An Overview

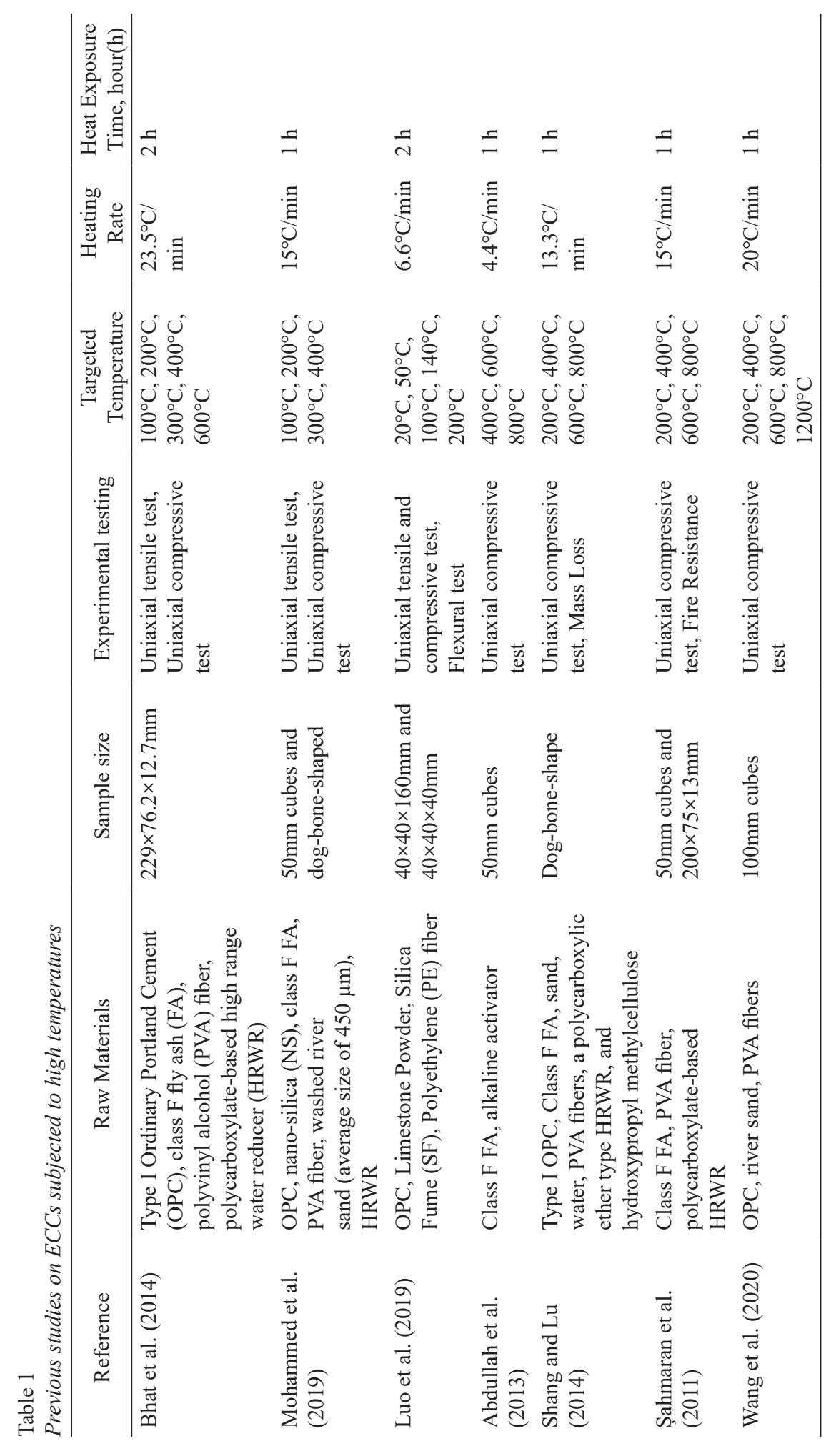

Pertanika J. Sci. \& Technol. 30 (1): 433 - 449 (2022) 


\section{METHODOS}

A systematic literature review approach was employed to overview the microstructural behavior of ECCs after being subjected to elevated temperatures. This approach has been broadly used in many research works and can directly provide important findings from the existing field of knowledge (Ren et al., 2020). In addition to a systematic and comprehensive search to find all previous studies relevant to the research topic, this approach includes explicit criteria that can include or exclude studies to ensure the quality search of the literature. The review protocol for this study is illustrated in Figure 1.

Generally, the protocol consists of two main phases. In the first phase, the data for the bibliographic of the study of microstructure analysis on ECC subjected to elevated temperature was done from a complete retrieval from online databases in Scopus. Scopus is easily accessible, available in the organization subscriptions as well as it is notably with good coverage of publications at sufficiently high quality. The selections were then filtered to obtain the actual trend of the research. The trend of publication year and research work allocation were the data aimed for the retrieval. Computerized databases were used as an approach to obtain this literature because this approach is more efficient and effective.

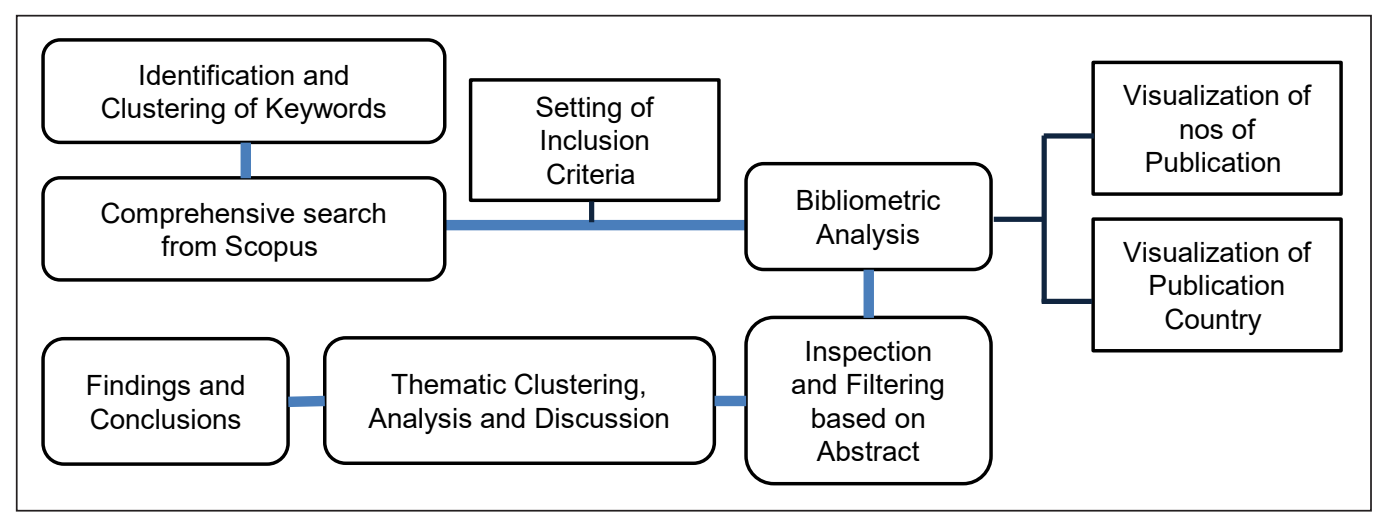

Figure 1. Review protocol

Table 2

Results of literature retrieval and selection

\begin{tabular}{llc}
\hline \multicolumn{1}{c}{ Steps } & \multicolumn{1}{c}{ Descriptions } & Records \\
\hline Logical & "ENGINEERED CEMENTITIOUS COMPOSITES" AND & \\
Statement & "ECC" AND ( "ELEVATED TEMPERATURE" OR "HIGH & \\
in Advance & TEMPERATURE" ) AND ( "MICROSTRUCTURAL" OR & Valid records (first- \\
Search & "MICROSTRUCTURE" OR "MICRO STRUCTURAL" OR & round filter): 90 \\
& "MICRO STRUCTURE" ) AND ( "scanned electron microscope" & \\
& OR "electron microscope" OR "XRD" OR "SEM" OR "EDS" ) & \\
$\begin{array}{l}\text { Inclusion } \\
\text { criteria }\end{array}$ & Publication years (2010 to Dec 2020), Type of publication: Article, & $\begin{array}{c}\text { Final records (second- } \\
\text { Keywords, subject area: engineering and material science. }\end{array}$ \\
& & 52 \\
\hline
\end{tabular}


The search started with all the literature based on the topics that related to the research's title. Then, the advanced search function in Scopus online collection database was used to search the related articles. Finally, keywords were used, such as Engineered Cementitious Composites, elevated temperature, microstructural, scanning electron microscope, and electron microscope. The actual coding for the advance search in Scopus is shown in Table 2.

The procedure followed the setting of inclusion criteria. These criteria include the publication years, publication types, refining keywords, and subject matters. Particularly, publication years were limited to 2010 to December 2020. The document types were confined to only research and review articles. Other types of literature, such as the book, conference paper, and book chapter, were not considered. Subject matters, such as engineering and materials science were included, and refining keywords, such as microstructure, scanning electron microscopy, engineered cementitious composite (ECC), elevated temperature, fire resistance, microcracks, microstructural analysis, micropores, $\mathrm{x}$-ray diffraction, fire exposures, matrix microstructure, microstructural characteristics and microcracking were included. Figure 2 shows the number of articles after applying the inclusion criteria.

The entire abstract from 52 articles recorded from the second-round filter was clustered according to the themes. Next, the themes were identified to answer the research questions, such as (1) What are the effects of the temperature on the compressive strength of ECC, and (2) What are the effects of elevated temperature on microstructural behavior of ECC? Finally, the articles that fit the themes of the study were chosen for further analysis, data discussion, and evaluation.

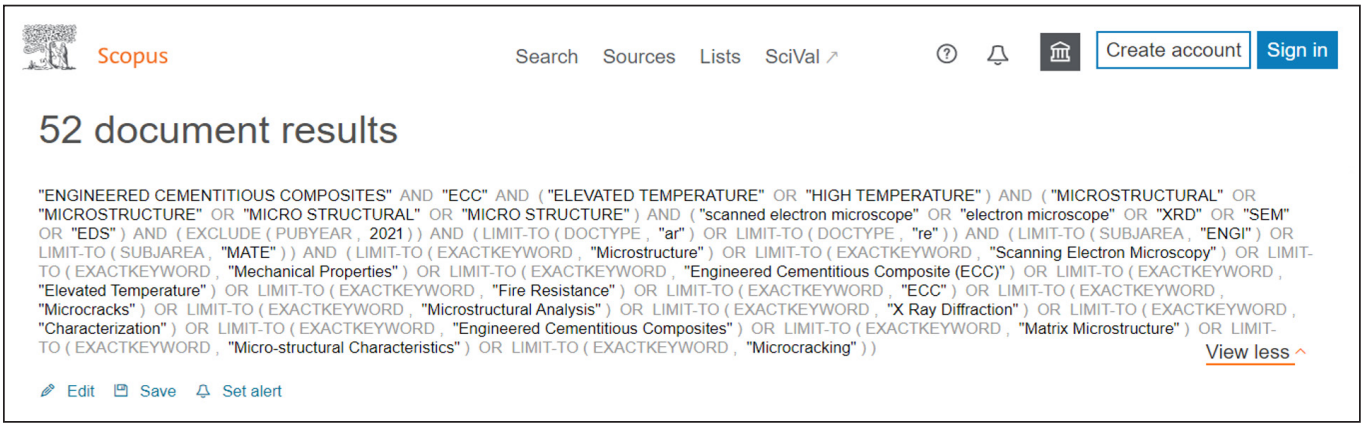

Figure 2. Logical statement and inclusion criteria (Image from Scopus online database)

\section{RESULTS AND DISCUSSION}

\section{Bibliometric Analysis}

Figure 3 shows the publications for the last ten years for the topics as filtered in Figure 2. Research related to the microstructural behavior of ECC after exposure to elevated 
temperature has gotten the attention of researchers in recent years. A significant increasing trend of publications can be seen from 2017 to 2020. The highest number of publications (16 nos) was recorded in 2020.

Figure 4 shows the statistical distribution of data number of publications per country for the last ten years. China has actively published articles and showed interest in the research regarding the exposure of ECC to elevated temperature (25 nos of publications), followed by the United States, recorded as 12 publications in years 2010-2020. On the other hand, very few works were done on this study in the countries of the Association of Southeast Asian Nations (ASEAN); only two publications were detected in Malaysia and Singapore, respectively.

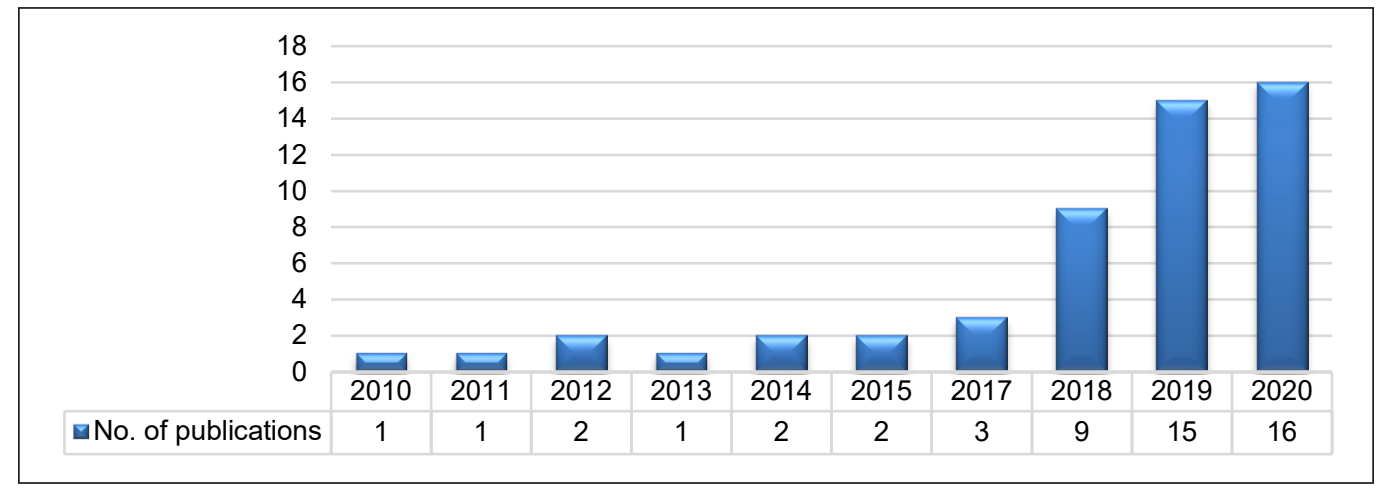

Figure 3. Numbers of publications per year (2010-2020)

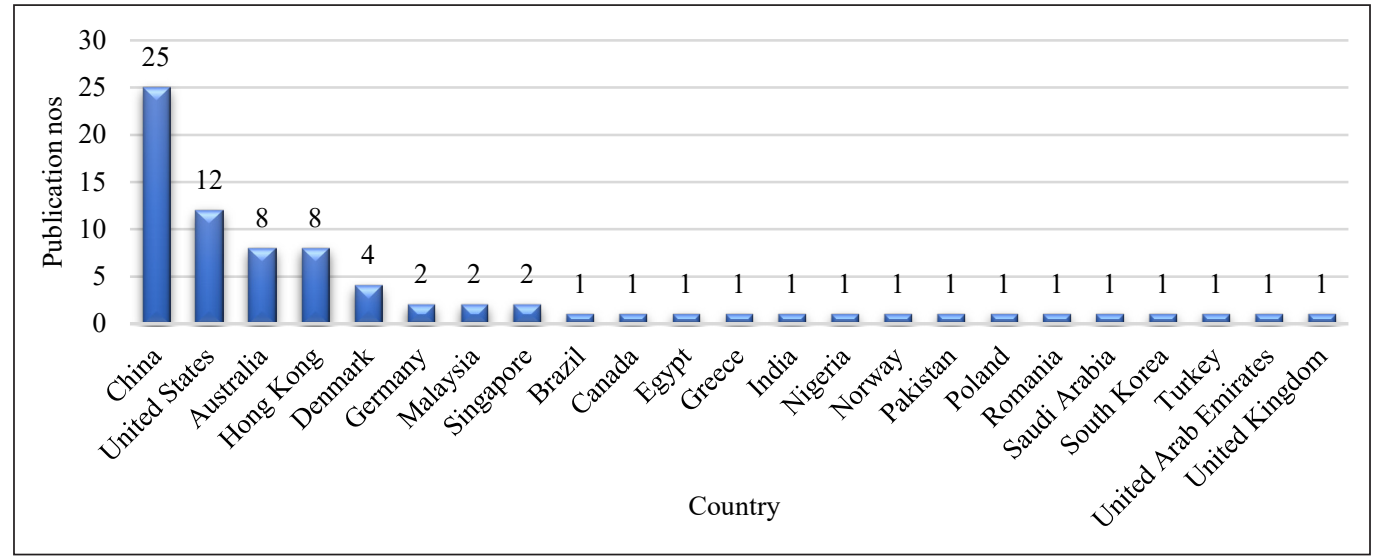

Figure 4. Statistical distribution of data number of publications per country

\section{Effect of Temperature on Compressive Strength}

Table 3 shows the compressive strength of ECCs after exposure to different temperatures. A decreasing trend in the compressive strength is observed when ECCs exposed to elevated temperatures starting from $200^{\circ} \mathrm{C}$. The decrement of the compressive strength is obvious 
Elevated Temperature on ECC Microstructural Behavior: An Overview

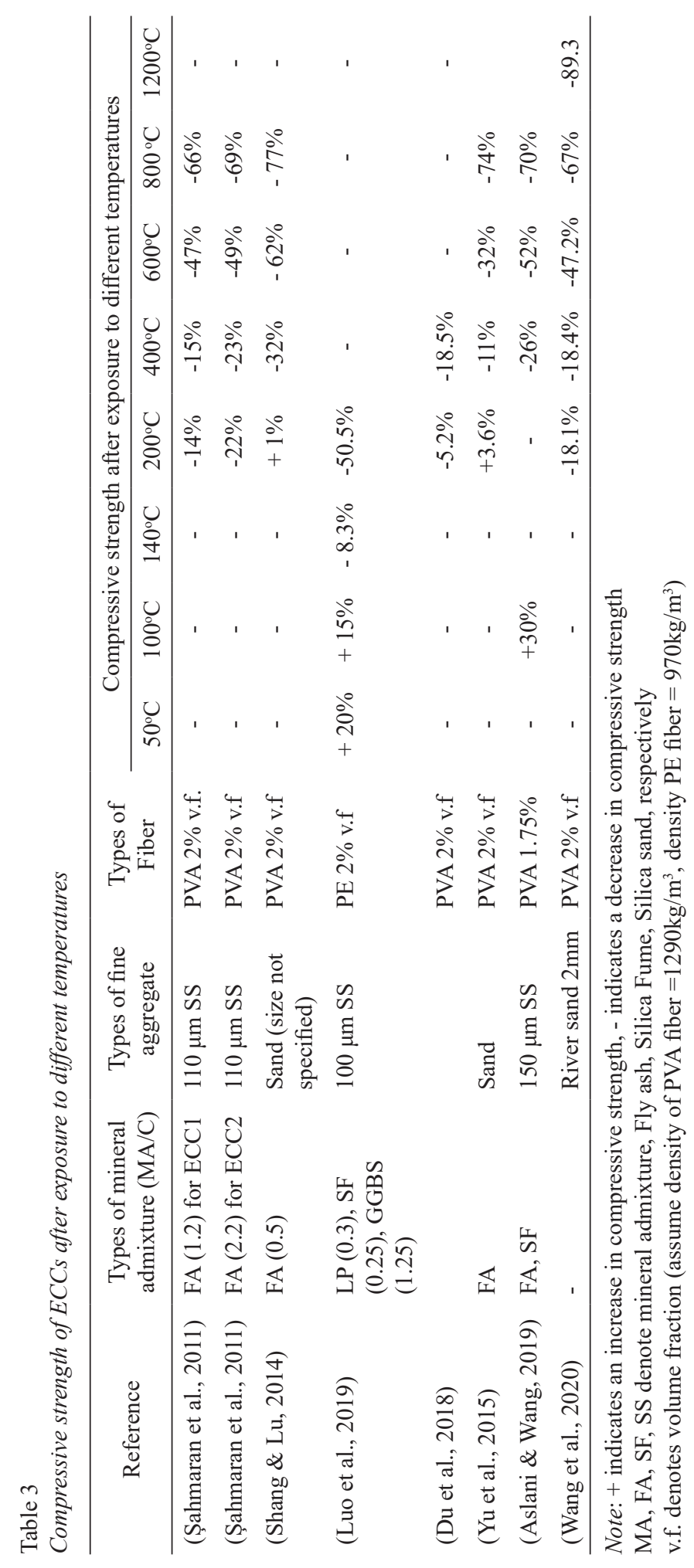

Pertanika J. Sci. \& Technol. 30 (1): 433 - 449 (2022) 
after $400^{\circ} \mathrm{C}$. Şahmaran et al. (2011) found a greater decrement in the compressive strength for ECC with higher fly ash volume at $200^{\circ} \mathrm{C}-400^{\circ} \mathrm{C}$, however no significant effect of fly ash volume in the reduction at $600^{\circ} \mathrm{C}-800^{\circ} \mathrm{C}$. According to Şahmaran et al. (2011), decreasing in compressive strength when exposed to $200^{\circ} \mathrm{C}$ is due to the hydration of fly ash particles, whereas at temperature $400^{\circ} \mathrm{C}$ is due to porosity increase and weight loss. ECC specimens demonstrated a great loss in compressive strength after being exposed at temperatures $600^{\circ} \mathrm{C}$ to $800^{\circ} \mathrm{C}$. A greater reduction in compressive strength, especially at temperature $400^{\circ} \mathrm{C}$ to $800^{\circ} \mathrm{C}$, was reported by Shang and $\mathrm{Lu}$ (2014) in their ECC specimens with lower fly ash content. When the ECC specimens were subjected to temperature $1200^{\circ} \mathrm{C}$, the decrement up to $89 \%$ compared to the one at room temperature was noticed.

Luo et al. (2019) found enhancement in compressive strength when the ECC specimen exposure to a temperature lesser than $100^{\circ} \mathrm{C}$. However, decreases steadily started from $50^{\circ} \mathrm{C}$ to $200^{\circ} \mathrm{C}$. The higher temperature increased the pore size and porosity of the specimen. The drastic change in the compressive strength was due to visible minor cracking and increase of porosity (Luo et al., 2019; Şahmaran et al., 2011; Shang \& Lu, 2014).

Heating duration can affect the residual mechanical properties of the specimen (Yu et al., 2015). For example, after being exposed for one hour at a temperature of $200^{\circ} \mathrm{C}$, the compressive strength increased 3.6\%. After two hours of exposer at the same temperature, the compressive strength of the specimen increased $11.5 \%$. The changes in the mechanical properties of the specimen at this temperature may be due to the reinforced hardened cement paste (HCP) during the evaporation of free water, leading to greater Van der Waal forces as the cement gel layers pass closer to each other. The same goes for the study by Aslani and Wang (2019), whereby the compressive strength increases 30\% after being exposed to $100^{\circ} \mathrm{C}$. The decreasing of the compressive strength at temperature $400 \mathrm{might}$ be due to small microcracks appearing and a drastic decrease of the compressive strength after exposer up to 600 , maybe because this temperature level was a critical temperature for strength loss in ECC specimens.

Exposure of ECCs to high temperatures tends to experience moisture loss, and this scenario causes the increment of the initial porosity of ECCs. The increasing porosity resulting from high temperature coarsens the pore size and subsequently gives a remarkably negative effect to the compressive strength (Luo et al., 2019; Şahmaran et al., 2011; Shang $\& \mathrm{Lu}, 2014)$. Melting of fiber in ECC at high temperature is the reason for the great number of pores and high porosity of the matrix. Figure 5 shows the cumulative pore volume of the ECC specimens after being exposed to the targeted temperature.

Most of the studies mentioned above investigated the strong performances of ECCs at exposure temperature $200^{\circ} \mathrm{C}$ and onwards. It is supported by Luo et al. (2019), where there are no significant changes in the strength before exposure to a temperature below $200^{\circ} \mathrm{C}$. Although many have provided strength performance data at a temperature range from $200^{\circ} \mathrm{C}-800^{\circ} \mathrm{C}$, ECCs investigated in these studies mainly incorporated PVA fiber at 


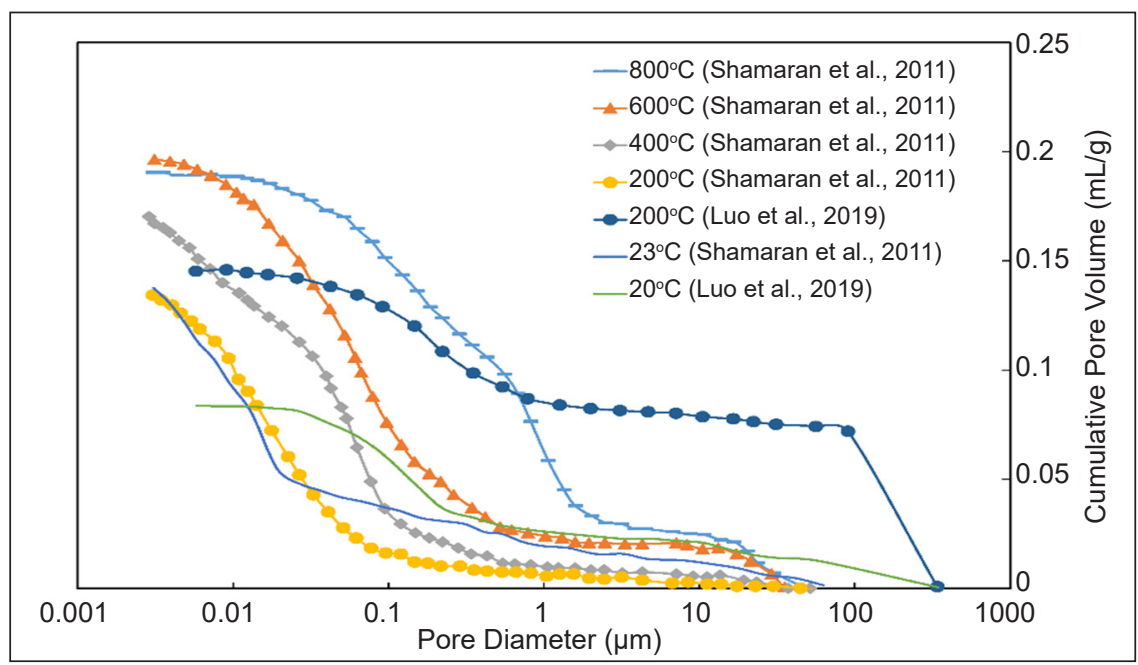

Figure 5. Cumulative pore volume of the sample before and after exposure to elevated temperature by (a) (Şahmaran et al., 2011), and (b) (Luo et al., 2019)

$2 \%$ volume faction. Findings on this topic for other fibers (i.e., steel, PE fibers) and their percentages are very limited. Additionally, incorporating the mineral admixtures in these studies is in wide options (i.e., fly ash, silica fume, slag). These findings hardly conclude that they provide a real understanding of the behavior of the ECCs when exposed to elevated temperatures.

\section{Microcracking and Fibre Deterioration}

Table 4 presents the effect of different temperature levels on the deterioration of fiber and the microstructural behavior of ECC. The heating regime is explained based on four main temperature ranges, namely $0^{\circ} \mathrm{C}-200^{\circ} \mathrm{C}, 201^{\circ} \mathrm{C}-400^{\circ} \mathrm{C}, 401^{\circ} \mathrm{C}-600^{\circ} \mathrm{C}$, and $601^{\circ} \mathrm{C}-800^{\circ} \mathrm{C}$. The melting point of PE fibers in ECC is observed at $150^{\circ} \mathrm{C}$, causing the increase of the porosity and the average pore size of the ECC specimen (Luo et al., 2019). On the other hand, the temperature effect on the microstructure of the fiber at $140^{\circ} \mathrm{C}$ caused the unrecoverable deformation, which affected the mechanical properties of the specimen. On the one hand, PVA fibers started to melt, and micropores began to appear at a temperature of $200^{\circ} \mathrm{C}$ (Bhat et al., 2014).

At temperature $400^{\circ} \mathrm{C}$, the PVA fibers have melted completely and created micropores and interconnected pores in the ECC microstructure (Bhat et al., 2014; Mohammed et al., 2019; SSahmaran et al., 2011; Shang \& Lu, 2014). More micropores were observed in the specimen that was exposed to a temperature level of $600^{\circ} \mathrm{C}$. The average pore diameter size of the ECC specimen exposed to a temperature of $600^{\circ} \mathrm{C}$ rapidly changes caused by the totally melted fibers and water evaporation. The magnification of SEM by Bhat et al. (2014) was chosen to illustrate the effect of temperature on the PVA fiber (Figure 6). 
For instance, microstructure did not experience any changes at temperature $20^{\circ} \mathrm{C}$ (Figure 6a). Fiber started to melt, and micropores appeared at $200^{\circ} \mathrm{C}$ (Figure $6 \mathrm{~b}$ ) while the fiber completely melted, and more micropores appeared at $400^{\circ} \mathrm{C}$ to $800^{\circ} \mathrm{C}$ (Figures $6 \mathrm{c}$ and $6 \mathrm{~d}$ ). Similar findings were reported by Wang et al. (2020), and three mechanisms were claimed to play roles: the effects of thermal expansion, volume expansion due to chemical reactions, and coarsening of pore structure.

The crystalline calcium hydroxide $(\mathrm{CH})$ started to disappear after the specimen was exposed to a temperature of $100^{\circ} \mathrm{C}$ (Mohammed et al., 2019). After exposure at a temperature of $200^{\circ} \mathrm{C}$, tiny micro-cracks started to visible. The number and size of the micro cracks at this temperature also increase (Shang \& Lu, 2014). Conversely, Şahmaran et al. (2011) reported no significant changes in the microstructure, and micro-cracks were not apparent at a temperature of $200^{\circ} \mathrm{C}$.

Specimens exposed to the temperature of $300^{\circ} \mathrm{C}$ and $400^{\circ} \mathrm{C}$ became porous. The more micro-crack appeared at this temperature level due to the melted PVA fibers, dehydration, and degradation of the cementitious material (Mohammed et al., 2019). However, microcrack only started to be visible at $400^{\circ} \mathrm{C}$ in ECCs (Abdullah et al., 2013; Şahmaran et al., 2011).

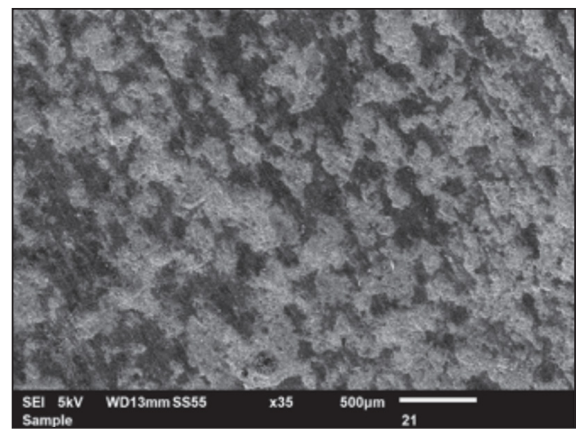

(a)

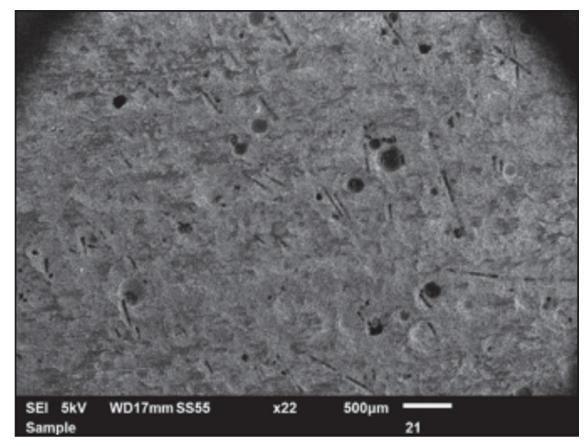

(c)

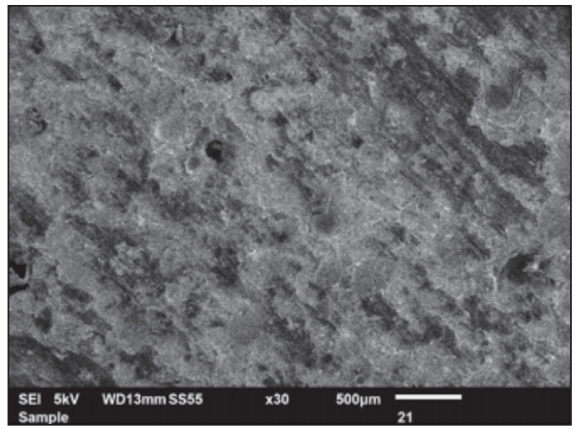

(b)

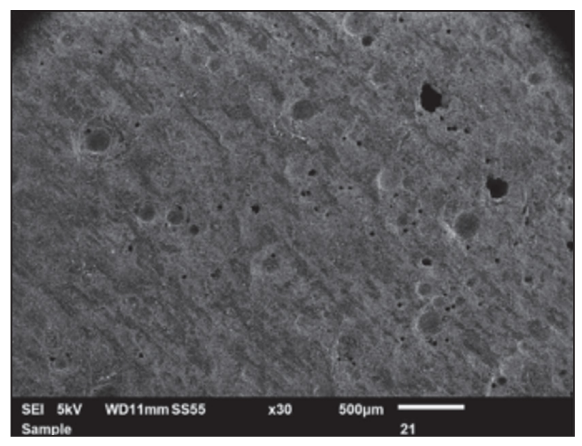

(d)

Figure 6. Magnification scanning electron microscopy of ECC subjected to elevated temperature: (a) $20^{\circ} \mathrm{C}$; (b) $200^{\circ} \mathrm{C}$; (c) $400^{\circ} \mathrm{C}$; and (d) $600^{\circ} \mathrm{C}$ (Bhat et al., 2014) 
At a temperature of $600^{\circ} \mathrm{C}$ and $800^{\circ} \mathrm{C}$, rough heterogeneous with a larger proportion of pores appear. The visibility of rough pores at higher temperatures is due to the sintering process (Abdullah et al., 2013). At a higher a temperature of $600^{\circ} \mathrm{C}$ and $800^{\circ} \mathrm{C}$, a wider micro-cracks appearance and a larger pore proportion due to the rate of water evaporation of the sample is high and the sintering process also high (Abdullah et al., 2013). The microstructure of the specimen exposed to a temperature of $800^{\circ} \mathrm{C}$ started to lose the crystalline strictures characteristic (Şahmaran et al., 2011; Shang \& Lu, 2014).

Porosity increased after the specimen was exposed to temperature $200^{\circ} \mathrm{C}$ due to the pore water in the specimen starting to lose (Du et al., 2018). The melting of the PVA fiber at temperature $300^{\circ} \mathrm{C}$ created the amount of the pores to become larger. As the temperature increased, the amount of melted fiber also increased. PVA fiber completely melted after exposer at a temperature of $400^{\circ} \mathrm{C}$. The surface of the fiber was moderately ruined; however, but the PVA fiber was observed not melting after exposure to a temperature of 200 (Yu et al., 2015). The fiber was completely melted at temperature $400^{\circ} \mathrm{C}$, creating more pores and microcracks increased. The specimen loses its crystalline characteristic after being exposed to a temperature up to 800 (Aslani \& Wang, 2019; Yu et al., 2015).

\section{CONCLUSION}

This paper presents quantitative bibliographic data derived from scientific publications and an overview of Engineered Cementitious Composites subjected to elevated temperature. There have been very limited studies on this topic for the past ten years. However, an increasing trend in the number of publications over the years reveals the importance and relevancy of the topic in the future, particularly in the construction industry.

The exposure of the ECC specimens to elevated temperatures can influence the mechanical properties of concrete, particularly in compressive strength. Most of the studies showed a decrement in compressive strength after being exposed to a temperature at $200^{\circ} \mathrm{C}$ onwards. It is found from previous researchers' findings that the decrement in compressive strength is due to the increase of pores, which are mainly caused by the evaporation of water and melting of fibers. The melting point of Polyethylene (PE) fibers at $150^{\circ} \mathrm{C}$ and Polyvinyl alcohol (PVA) fibers in between $201^{\circ} \mathrm{C}-400^{\circ} \mathrm{C}$ were reported. After the fibers started to melt, the microstructure behavior of the specimen changed, such as crystalline characteristics, pores, and microcracking was observed.

The residual properties of the specimen drop moderately after the ECC specimen is exposed to elevated temperature. Apparent microcracking and explosive spalling occurred in specimens subjected to elevated temperature compared to the unheated samples. When the temperature increases, micro-crack size dramatically increases and results in plastic behavior and unrecoverable shapes of fibers. 
Mohamad Hakimin Khazani, Oh Chai Lian, Lee Siong Wee, Mohd Raizamzamani Md Zain and Norrul Azmi Yahya

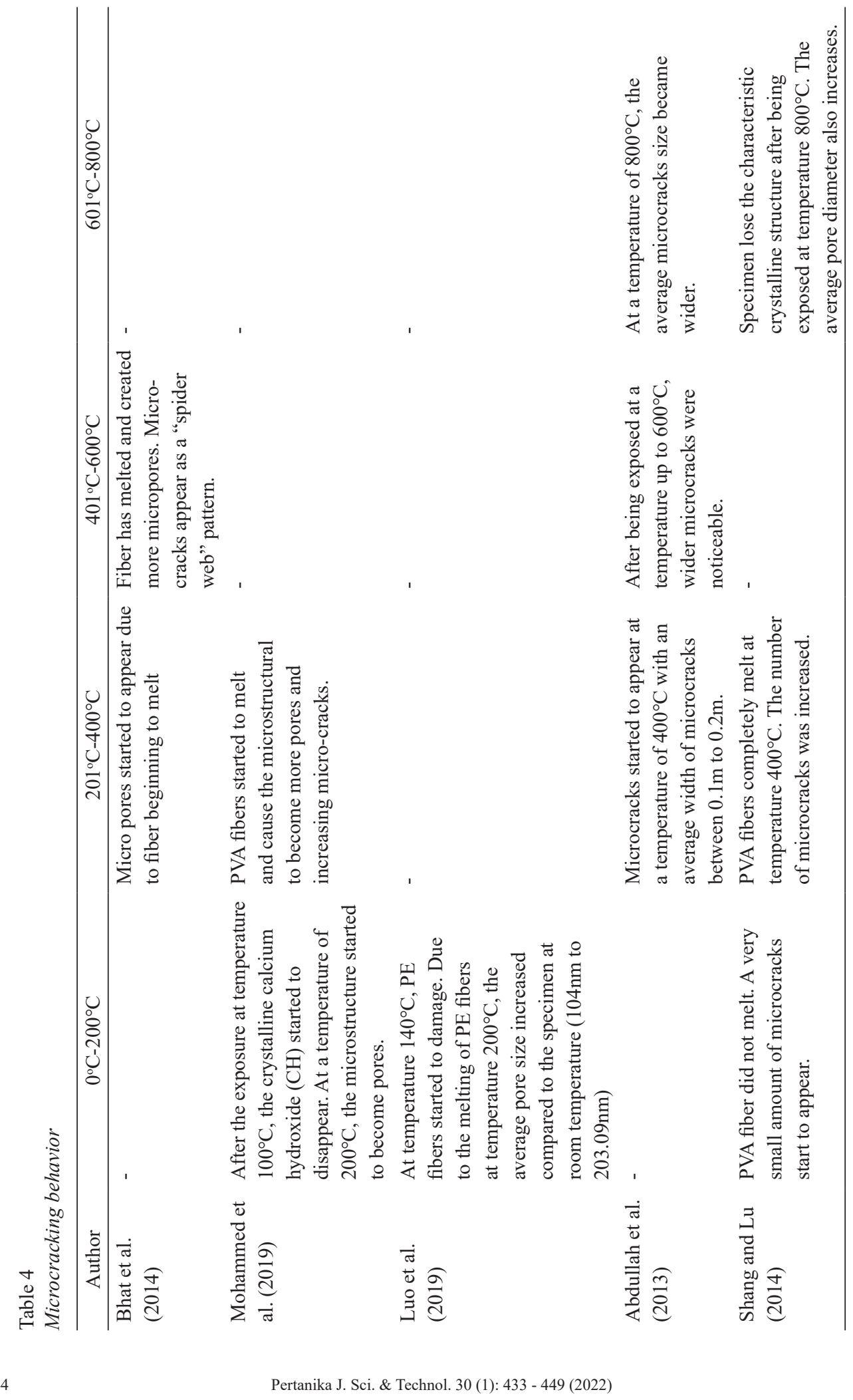


Elevated Temperature on ECC Microstructural Behavior: An Overview

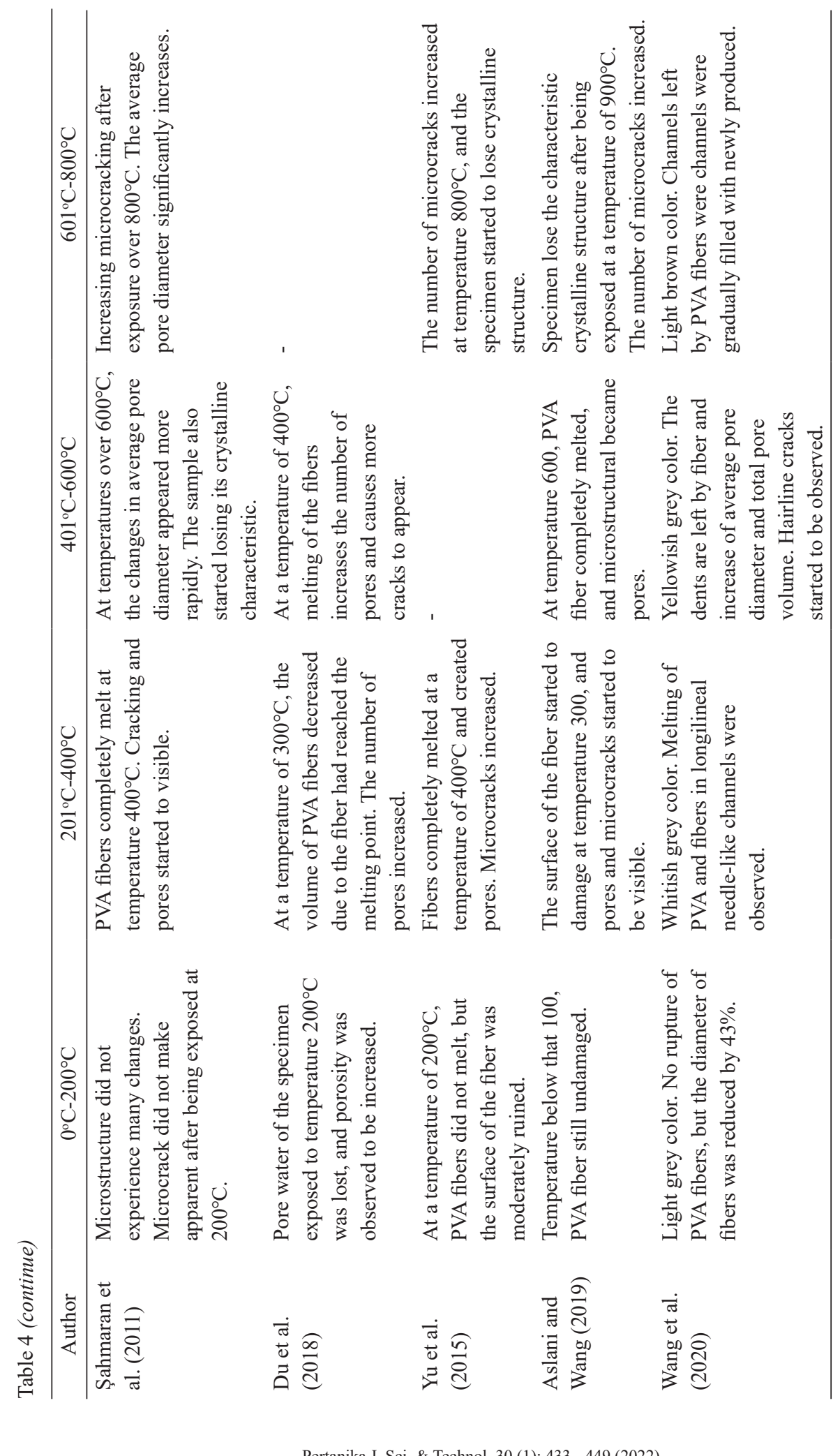

Pertanika J. Sci. \& Technol. 30 (1): 433 - 449 (2022) 
Based on the previous research findings towards engineered cementitious composite subjected to elevated temperature, the paper makes recommendations on a few future perspectives of research with the aims to improve the current knowledge of findings:

- Advanced engineered cementitious composite. In recent years, significant numbers of smart, green, and innovative materials or techniques, such as hollow glass microspheres (Aslani et al., 2021), ceramic polishing brick powder (Xiong et al., 2021), microbially induced calcium carbonate precipitation using Aerobic nonureolytic bacteria (Justo-Reinoso et al., 2021) have been utilized into ECC to enhance the material sustainability in the construction industry. However, studies on the effects of these materials on the strength and durability performances of the ECC subjected to elevated temperature are very new research and need to be conducted.

- Advanced microstructural characterization techniques. Many advanced techniques were recently proposed in examining microstructural characteristics of a material, such as the machine-based learning method (Chan et al., 2020; Liu et al., 2021) and deep convolutional neural networks (Dong et al., 2020). New potential methods need to be explored to obtain a better understanding of the microstructural characteristics of the ECC after being exposed to elevated temperatures.

\section{ACKNOWLEDGMENTS}

The Universiti Teknologi MARA funded this research under grant Research Entity Initiative (REI) 600-IRMI/REI 5/3 (012/2018).

\section{REFERENCES}

Abdullah, M. M. A. B., Kamarudin, H., Nizar, K., Razak, R., Yahya, Z., \& Abdullah, A. (2013). Microstructure studies on the effect of the alkaline activators of fly ash-based geopolymer at elevated heat treatment temperature. Applied Mechanics and Materials, 421, 342-348. https://doi.org/10.4028/www.scientific. net/AMM.421.342

Aslani, F., Dehghani, A., \& Wang, L. (2021). The effect of hollow glass microspheres, carbon nanofibers and activated carbon powder on mechanical and dry shrinkage performance of ultra-lightweight engineered cementitious composites. Construction and Building Materials, 280, Article 122415. https://doi.org/ https://doi.org/10.1016/j.conbuildmat.2021.122415

Aslani, F., \& Wang, L. (2019). Fabrication and characterization of an engineered cementitious composite with enhanced fire resistance performance. Journal of Cleaner Production, 221, 202-214. https://doi.org/https:// doi.org/10.1016/j.jclepro.2019.02.241

Bhat, P. S., Chang, V., \& Li, M. (2014). Effect of elevated temperature on strain-hardening engineered cementitious composites. Construction and Building Materials, 69, 370-380. https://doi.org/https://doi. org/10.1016/j.conbuildmat.2014.07.052 
Booya, E., Gorospe, K., Das, S., \& Loh, P. (2020). The influence of utilizing slag in lieu of fly ash on the performance of engineered cementitious composites. Construction and Building Materials, 256, Article 119412. https://doi.org/https://doi.org/10.1016/j.conbuildmat.2020.119412

Chan, H., Cherukara, M., Loeffler, T. D., Narayanan, B., \& Sankaranarayanan, S. K. (2020). Machine learning enabled autonomous microstructural characterization in 3D samples. Computational Materials, 6(1), 1-9. https://doi.org/https://doi.org/10.1038/s41524-019-0267-z

Chen, Z., Yang, Y., \& Yao, Y. (2013). Quasi-static and dynamic compressive mechanical properties of engineered cementitious composite incorporating ground granulated blast furnace slag. Materials \& Design, 44, 500-508. https://doi.org/https://doi.org/10.1016/j.matdes.2012.08.037

Dong, Y., Su, C., Qiao, P., \& Sun, L. (2020). Microstructural crack segmentation of three-dimensional concrete images based on deep convolutional neural networks. Construction and Building Materials, 253, Article 119185. https://doi.org/https://doi.org/10.1016/j.conbuildmat.2020.119185

Du, Q., Wei, J., \& Lv, J. (2018). Effects of high temperature on mechanical properties of polyvinyl alcohol engineered cementitious composites (PVA-ECC). International Journal of Civil Engineering, 16(8), 965-972. https://doi.org/10.1007/s40999-017-0245-0

Guan, Y., Wu, J., Sun, R., Zhang, H., Hu, Y., \& Wang, F. (2021). Transverse flexural behaviour of steelengineering cementitious composites (ECC) composite deck under negative and positive bending forces. KSCE Journal of Civil Engineering, 25(8), 2962-2973. https://doi.org/10.1007/s12205-021-1053-2

Huang, B. T., Dai, J. G., Weng, K. F., Zhu, J. X., \& Shah, S. P. (2021). Flexural performance of UHPC-concreteECC composite member reinforced with perforated steel plates. Journal of Structural Engineering, 147(6), Article 04021065. https://doi.org/10.1061/(ASCE)ST.1943-541X.0003034

Huang, T., \& Zhang, Y. X. (2014). Simulation of material behaviour of engineered cementitious composites under uniaxial tension. In L. Ye (Ed.), Recent Advances in Structural Integrity Analysis - Proceedings of the International Congress (APCF/SIF-2014) (pp. 539-543). Woodhead Publishing. https://doi.org/ https://doi.org/10.1533/9780081002254.539

Justo-Reinoso, I., Heath, A., Gebhard, S., \& Paine, K. (2021). Aerobic non-ureolytic bacteria-based self-healing cementitious composites: A comprehensive review. Journal of Building Engineering, 42, Article 102834. https://doi.org/https://doi.org/10.1016/j.jobe.2021.102834

Khan, M., Zhang, Y., \& Lee, C. (2021). Mechanical properties of high-strength steel-polyvinyl alcohol hybrid fibre engineered cementitious composites. Journal of Structural Integrity and Maintenance, 6(1), 47-57. https://doi.org/https://doi.org/10.1080/24705314.2020.1823558

Lee, S. W., Oh, C. L., \& Zain, M. R. M. (2019). Mechanical properties of engineered cementitious composites using local ingredients. Journal of Mechanical Engineering, 16(2), 145-157. https://doi.org/10.21491/ jmeche.v16i2.15332

Lee, S. W., Tan, K. H., \& Yang, E. H. (2018). Seismic behaviour of interior reinforced-concrete beam-column sub-assemblages with engineered cementitious composites. Magazine of Concrete Research, 70(24), 1280-1296. https://doi.org/https://doi.org/10.1680/jmacr.17.00359

Li, V. C. (2003). On engineered cementitious composites (ECC) a review of the material and its applications. Journal of Advanced Concrete Technology, 1(3), 215-230. https://doi.org/10.3151/jact.1.215 
Liu, F., Xu, K., Ding, W., Qiao, Y., \& Wang, L. (2021). Microstructural characteristics and their impact on mechanical properties of steel-PVA fiber reinforced concrete. Cement and Concrete Composites, 123, Article 104196. https://doi.org/https://doi.org/10.1016/j.cemconcomp.2021.104196

Luo, J., Cai, Z., Yu, K., Zhu, W., \& Lu, Z. (2019). Temperature impact on the micro-structures and mechanical properties of high-strength engineered cementitious composites. Construction and Building Materials, 226, 686-698. https://doi.org/https://doi.org/10.1016/j.conbuildmat.2019.07.322

Ma, H., Qian, S., Zhang, Z., Lin, Z., \& Li, V. C. (2015). Tailoring engineered cementitious composites with local ingredients. Construction and Building Materials, 101, 584-595. https://doi.org/10.1016/j. conbuildmat.2015.10.146

Mohammed, B. S., Achara, B. E., Liew, M. S., Alaloul, W. S., \& Khed, V. C. (2019). Effects of elevated temperature on the tensile properties of NS-modified self-consolidating engineered cementitious composites and property optimization using response surface methodology (RSM). Construction and Building Materials, 206, 449-469. https://doi.org/https://doi.org/10.1016/j.conbuildmat.2019.02.033

Qudah, S., \& Maalej, M. (2014). Application of engineered cementitious composites (ECC) in interior beamcolumn connections for enhanced seismic resistance. Engineering Structures, 69, 235-245. https://doi. org/https://doi.org/10.1016/j.engstruct.2014.03.026

Ren, R., Hu, W., Dong, J., Sun, B., Chen, Y., \& Chen, Z. (2020). A systematic literature review of green and sustainable logistics: bibliometric analysis, research trend and knowledge taxonomy. International journal of environmental research and public health, 17(1), Article 261. https://doi.org/https://doi.org/10.3390/ ijerph17010261

Şahmaran, M., Özbay, E., Hasan, E. Y., Lachemi, M., \& Victor, C. L. (2011). Effect of fly ash and PVA fiber on microstructural damage and residual properties of engineered cementitious composites exposed to high temperatures. Journal of Materials in Civil Engineering, 23(12), 1735-1745. https://doi.org/10.1061/ (asce)mt.1943-5533.0000335

Shang, X., \& Lu, Z. (2014). Impact of high temperature on the compressive strength of ECC. Advances in Materials Science and Engineering, 2014, Article 919078. https://doi.org/10.1155/2014/919078

Wang, Q., Yao, B., \& Lu, R. (2020). Behavior deterioration and microstructure change of polyvinyl alcohol fiber-reinforced cementitious composite (PVA-ECC) after exposure to elevated temperatures. Materials, 13(23), Article 5539. https://doi.org/10.3390/ma13235539

Xiong, Y., Xu, G., Wu, D., Fang, S., \& Tang, Y. (2021). Investigation of using the ceramic polishing brick powder in engineered cementitious composites. Journal of Building Engineering, 43, Article 102489. https://doi.org/https://doi.org/10.1016/j.jobe.2021.102489

Yang, X., Xu, L., \& Pan, J. (2021). Mechanical behavior of full-scale composite steel plate shear wall restrained by ECC panels. Journal of Building Engineering, 44, Article 102864. https://doi.org/https:// doi.org/10.1016/j.jobe.2021.102864

Yu, K. Q., Dai, J. G., Lu, Z. D., \& Leung, C. K. Y. (2015). Mechanical properties of engineered cementitious composites subjected to elevated temperatures. Journal of Materials in Civil Engineering, 27(10), Article 04014268. https://doi.org/10.1061/(ASCE)MT.1943-5533.0001241 
Yuan, F., Chen, M., \& Pan, J. (2020). Flexural strengthening of reinforced concrete beams with high-strength steel wire and engineered cementitious composites. Construction and Building Materials, 254, Article 119284. https://doi.org/10.1016/j.conbuildmat.2020.119284

Zhang, J., Leung, C. K. Y., \& Cheung, Y. N. (2006). Flexural performance of layered ECC-concrete composite beam. Composites Science and Technology, 66(11), 1501-1512. https://doi.org/https://doi.org/10.1016/j. compscitech.2005.11.024

Zhang, N., Gu, Q., Dong, Y., Qian, J., \& Zheng, Y. (2021). Seismic performance of bridges with ECC-reinforced piers. Soil Dynamics and Earthquake Engineering, 146, Article 106753. https://doi.org/https://doi. org/10.1016/j.soildyn.2021.106753 
